\title{
SELECTION OF PROJECTS FOR FORMATION OF A PORTFOLIO OF INVESTMENT PROJECTS
}

\author{
Roman Karpovich* \\ School of Management \\ Belarus State Economic University \\ Minsk, Belarus \\ E-mail: ramonak@ya.ru \\ Oksana Karpovich \\ Polyclinic №5 \\ Minsk, Belarus \\ E-mail: mirace@yandex.ru
}

\begin{abstract}
In article the example of construction of an analytical network for formation of a portfolio of investment projects is considered. Selection of criteria for an estimation of appeal of investment of the project is led. A numerical example is also presented to illustrate the new modelling idea and the proposed new algorithm.
\end{abstract}

Keywords: Creating project portfolio, ranging projects, analytic network process.

\section{Introduction}

In the Republic of Belarus the steady course on support of investment activity was established. Structures which dispose of financial streams of the state are created. On the other hand: activity of private investors becomes simpler. As a rule, the investor does not stop on any one project. It leads to a problem of formation of an optimum portfolio of investment projects. These investments go to various sectors of economy. The most attractive is the service sphere.

Formation of a portfolio of investments, according to the international practice, is carried out proceeding from system of the priority purposes, from which maintenance of projected object with investment resources is main. The investment portfolio of the private investor is capital-intensive, liquid, less risky in connection with duration of realization, and also difficult and labour-consuming in management. It defines high level of requirements to formation of an investment portfolio of real projects.

In this article we will consider formation of a portfolio of investment projects on an investment example in variety of fields.

The private sector has considered financial benefits in new conditions and has started to fill the market of custom services and has started to do necessary investments.

The enterprise problem consists in a choice of the most effective and safe projects which create the greatest increase in value of actions of a pas financing unit.

The analysis of an internal and external environment of the project is very important for following to market tendencies. Only being based on the good analysis of an existing and future situation, the investor can make successful decisions.

\footnotetext{
* Corresponding author
} 
The investor can effectively distribute the resources only by means of the scientific approach. During a decision-making stage many criteria of an estimation of the project and the decision on inclusion in a portfolio are considered should be based on these criteria. The quantity of criteria and alternatives increases and becomes difficult also it is almost impossible to analyse communications between all alternatives and criteria and to make decisions. In that case it is necessary to use a technique of decision-making with set of criteria. Thomas Saaty has developed a analytic network process (ANP) of which we can take advantage.

Formation of an investment portfolio of capital investments should provide: capital growth; income growth; minimisation of investment risks; sufficient liquidity of an investment portfolio.

The system of planning of an investment portfolio has appointment to generate such portfolio of industrial investments which will promote the maximum growth of financial stability of the enterprise.

Application of the system approach to definition of economic efficiency of investment projects of the timber industry enterprise allows to formulate following basic investigation phases:

1. Statement of a problem of formation of an optimum investment portfolio: a choice of investigated system and definition of its borders, the formulation of the purposes of management.

2. Drawing up the model of system planning of an investment portfolio through definition of parameters of system and management

3. The Choice of a method of the decision of a problem of formation of an optimum investment portfolio.

4. Forecasting of movement of system: definition of possible alternatives depending on operating possibilities.

The decision of an optimising problem means search of optimum alternative. To each alternative corresponds:

- The unique and accurately certain condition of system and its estimation on value of criterion function. In this case it is considered that decision-making occurs in the conditions of definiteness;

- $\quad$ Some outcomes, and each of them have some probability of occurrence. Consider that the decision is accepted in the conditions of risk.

- $\quad$ Some outcomes for which probabilities of occurrence or any preferences are not defined. In this case the decision is accepted in the conditions of uncertainty.

\section{Literature review}

Now there are many approaches to formation of a portfolio of investment projects. Jiuping Xu (2009) has applied indistinct casual variables to formation of a varying portfolio of investments, Hau-San Wong (2009) used self-adjustable algorithm using feigned normalised algorithm, neural networks and modelling by indistinct technicians, Wei-Guo Zhang (2007) has created model on the bottom both top likelihood averages and dispersions, Xiaoxia Huang (2008) has made risk definition in indistinct sets and used model of averagebrave curves and indistinct programming, Alberto Fernández (2007) for a choice of a portfolio of investments used linear programming, neural networks and the approach based on the analysis of expected average values and variations of random variables, based on a technique Markowitz, Xiaoxia Huang (2006) has included in genetic algorithm stochastic variables with the indistinct information. In our work with Olga A. Siniavskaya, Boris A. Zhelezko (2009) there is method connected to plan stock exchange portfolio. 


\section{Discussion of a question or problem by means of a method}

Our model urged to range projects on appeal of investment. Following projects are estimated: Cleaning Rust, Pellets Factory, Smart House, Sport Cars.

1. Cleaning Rust - "Unique technology on clearing of metal rolling of a rust and scale" (further "DRUM"). On the basis of the invention "DRUM" the high-grade alternative metal-grit stream technologies of processing of surfaces of metal rolling is developed. The technology "ДРУМ" has overwhelming advantages on all indicators in comparison with metal-grit stream technology. Also thanks to the innovative mechanism there are possibilities for creation and realisation of several new industrial products/services on its basis and having demand.

2. Pellets Factory - Creation of the enterprise for manufacture of fuel granules (Pellets).

One biomass fuel that has gained national attention with rising fossil fuel prices is wood pellets. Wood pellets are compressed by-products from the forest products industry, often woodchips and sawdust. They are a locally available and a cost-effective heating fuel with several advantages over other types of biomass. Wood pellets are a condensed uniformly sized form of biomass energy, making them easier to store and use than many other biomass fuels. Pellet heating technology is also quite simple, minimizing operation and maintenance requirements. These heating systems can be easy to plan for and install and can save a building owner thousands of dollars in energy costs over time while providing significant local economic and environmental benefits.

3. Smart House - Working out and manufacture of the electronic complete set for automation and monitoring of all electro-household appliances, the climate control, protection and power savings, etc. the Product should be a set of the distributed modules united in a network and operated with central panel or distantly. Initial application in apartments and private houses.

4. Sport Cars - Creation of the enterprise performing following works:

- $\quad$ working out, manufacturing of cars under the individual project (sketch).

- $\quad$ manufacturing of retro-cars on the sample.

- $\quad$ guarantee and after guarantee service of the made cars.

- $\quad$ Manufacturing of sets (do-it-yourself kit), for independent assemblage of a product.

- $\quad$ Sale of original spare parts, repair of the made cars.

- $\quad$ restoration of collection, antiquarian and rare cars.

\section{4 .Our model}

We are used multiplicative formula at the top hierarchy of BOCR.

The basic criteria of selection of investment projects at competition carrying out are conformity of the investment project to following priority directions:

- $\quad$ Creation, development and expansion of manufacture of the goods (works, services);

- $\quad$ The organisation, manufacture development focused on export, replacing import production;

- $\quad$ The production, directed on power- and resources- economy;

- Introduction of new technologies;

- $\quad$ An urgency and perspectives of the investment project, its end result;

- $\quad$ Planned attraction of means for realisation of the investment project from other sources;

- $\quad$ Prospective quantity of new workplaces and validity of their creation. 
Following described above parameters we have created next decision networks with hierarchical structure of each merit. (Figure 1). Table 1 lists the clusters in the decision networks and the elements in each cluster.

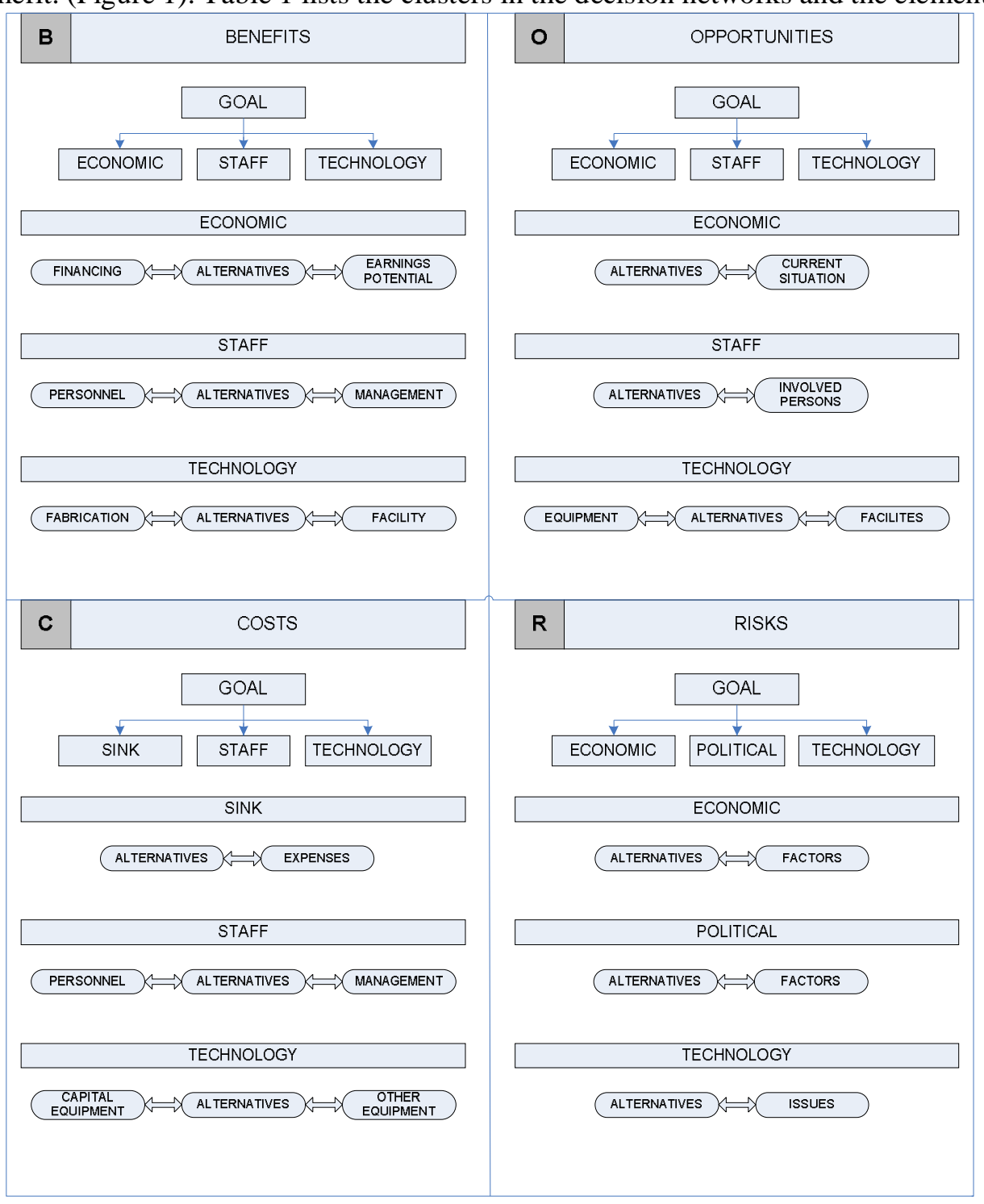

Figure 1. Control Criteria and Decision Networks.

Table 1. Clusters in the Decision Networks and Elements in the Clusters

\begin{tabular}{|c|c|c|c|}
\hline BOCR & Control criteria & Clusters & Elements \\
\hline \multirow{4}{*}{ 营 } & \multirow[t]{2}{*}{ Economic } & Financing & $\begin{array}{l}\text { Capital Investments } \\
\text { Joint Investments }\end{array}$ \\
\hline & & Earnings potential & $\begin{array}{l}\text { Between } \$ 50^{\prime} 000 \text { and } \$ 100^{\prime} 000 \text { annually } \\
\text { Less than } \$ 50^{\prime} 000 \text { annually } \\
\text { More than } \$ 100^{\prime} 000 \text { annually }\end{array}$ \\
\hline & \multirow[t]{2}{*}{ Staff } & Personnel & $\begin{array}{l}\text { Skilled workers } \\
\text { Technology staff } \\
\text { Unskilled workers }\end{array}$ \\
\hline & & Management & Plant manager \\
\hline
\end{tabular}


R. Karpovich, O. Karpovich

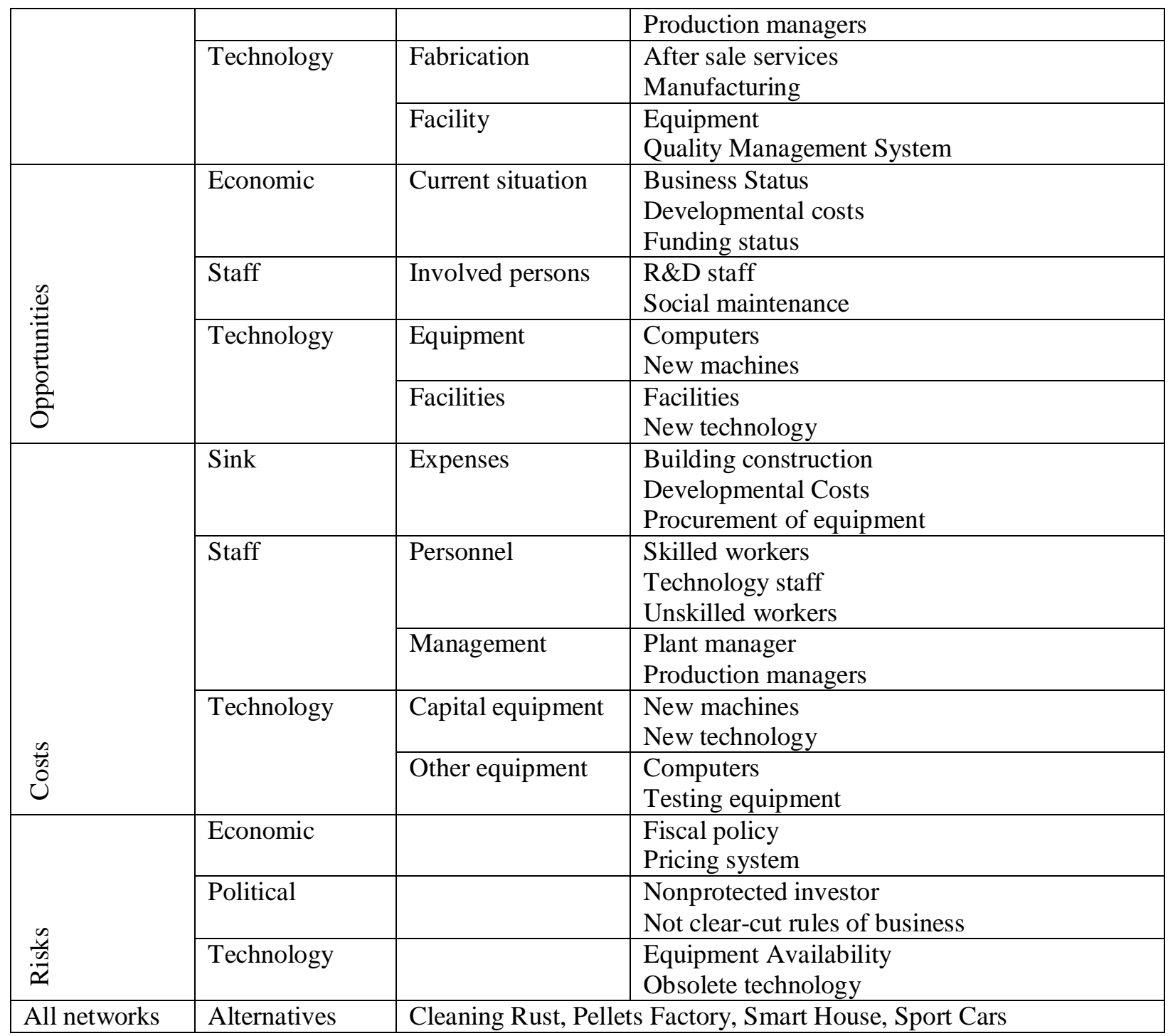

\section{Results and discussion}

As a result of model processing have been received priorities on alternatives. This data is resulted in Table 2 and Table 3.

Table 2. Synthesis

\begin{tabular}{|l|l|l|l|l|}
\hline Alternatives & $\begin{array}{l}\text { Benefits } \\
0.3905\end{array}$ & $\begin{array}{l}\text { Opportunities } \\
0.2761\end{array}$ & $\begin{array}{l}\text { Costs } \\
0.1953\end{array}$ & $\begin{array}{l}\text { Risks } \\
0.1381\end{array}$ \\
\hline $\begin{array}{l}\text { Cleaning } \\
\text { Rust }\end{array}$ & 0.7049 & 0.3576 & 1.0000 & 0.2770 \\
\hline $\begin{array}{l}\text { Pellets } \\
\text { Factory }\end{array}$ & 0.9078 & 0.4336 & 0.3979 & 0.5140 \\
\hline Smart House & 0.9310 & 0.7951 & 0.9729 & 0.3814 \\
\hline Sport Cars & 1.0000 & 1.0000 & 0.6134 & 1.0000 \\
\hline
\end{tabular}

Table 3. Alternative Rankings 


\begin{tabular}{|l|l|}
\hline Alternatives & Ideals \\
\hline Cleaning Rust & 0.456310 \\
\hline Pellets Factory & 0.964828 \\
\hline Smart House & 1.000000 \\
\hline Sport Cars & 0.817256 \\
\hline
\end{tabular}

\section{Conclusions}

Thus, the most favourable to investment are Smart House and the Pellets Factory. Using multiplicative formula that was chosen why to predict short time period.

\section{REFERENCES}

Jun Li, Jiuping Xu (2009). A novel portfolio selection model in a hybrid uncertain environment. Omega, $37(2), 439-449$.

Xiang Li, Yang Zhang, Hau-San Wong, Zhongfeng Qinc (2009). A hybrid intelligent algorithm for portfolio selection problem with fuzzy returns. Journal of Computational and Applied Mathematics, 233 (2), 264-278.

Wei-Guo Zhang (2007). Possibilistic mean-standard deviation models to portfolio selection for bounded assets. Applied Mathematics and Computation, 189 (2), 1614-1623.

Xiaoxia Huang (2008). Risk curve and fuzzy portfolio selection. Computers \& Mathematics with Applications, 55(6), 1102-1112.

Alberto Fernández, Sergio Gómez (2007). Portfolio selection using neural networks. Computers \& Operations Research, 34(4), 1177-1191.

Xiaoxia Huang (2007). Two new models for portfolio selection with stochastic returns taking fuzzy information. European Journal of Operational Research, 180(1), 396-405.

Roman V. Karpovich, Olga A. Siniavskaya, Boris A. Zhelezko (2009). Creation of the Rating of Stock Market Analytical Systems on the Base of Expert Qualitative Estimations. Online Proceedings of the 10th International Symposium ISAHP 2009, ISSN 1556-8296. 